\title{
Reporting the climate change crisis
}

\section{Anabela Carvalho}

Cite this paper as:

Carvalho, A. (2010) 'Reporting the climate change crisis', in S. Allan (ed.) The Routledge Companion to News and Journalism Studies, pp. 485-495, Oxford: Routledge.

Climate change is one of the most serious threats that humankind will have to deal with in the coming decades. There is every indication that it will engender a significant upheaval in the climate patterns of the world regions, with corresponding impacts on agriculture, ecosystems and human health. This main entail unpredictable weather events, like storms and tornados, while posing significant risks for human security, destruction of housing and economic structures, and flooding of low lying countries, among other effects (IPCC 2007).

The enhanced greenhouse effect is a complex, multi-dimensional issue, both in terms of causes and effects. The production of greenhouse gases (GHGs), which strongly influence the Earth's climate, is deeply embedded in the way in which modern societies work: in transportation, heating, the production of goods, and so forth. Climate change has strong links with powerful economic activities and organizations, such as the oil industry. Therefore, tackling the problem requires an unprecedented level of coordination between governments, industry and consumers in a short time-scale.

The precise definition of the problem is itself a battlefield, where different actors - NGOs, corporations, scientific community, etc. - attempt to make their views prevail. This conceptual struggle will have material consequences, since the solutions are conditioned by what is understood to be the problem. The news media, as a key space for the production, reproduction and transformation of meanings, play an important role in this process, influencing both social representations and policy-making on this issue (e.g. Cabecinhas, Lázaro and Carvalho in press; Corbet and Durfee 2004; Wilson 1995).

This chapter focuses on the roles that the mainstream media have played in the last two decades in the social construction of climate change and in the relations between science, policy and public opinion. By mainstream media I mean the major television networks, newspapers and magazines with high circulation, and radio channels with significant audiencesi. Alternative media, such as community media, blogs, social movements' online news and other citizen-produced content on the internet, continue to grow in importance; however, the fragmented nature of the audiences of these media complicates the evaluation of their social impact and turns them into more difficult research objects than the traditional media. The chapter will discuss the challenges that climate change poses to the media, the dominant public and political discourses, and some of the emerging issues and questions to be addressed by researchers.

\section{The emergence and discursive control a novel global risk}

Although there were sporadic appearances of the 'greenhouse effect' in the media before 1988, that year was a turning point. This was due to a confluence of factors: a heat wave and intense drought in the USA; James Hansen's testimony to the US Senate Energy Committee that he was $99 \%$ certain that global warming was underway; and Margaret Thatcher's sudden interest in the issue (perhaps motivated by conflicts with the coal unions and the plan to invest in nuclear power) with dramatic statements made in a speech to the Royal Society. It was also in 1988 that the Intergovernmental Panel on Climate Change (IPCC) was formed. Levels of media attention paid to the issue fluctuated quite dramatically 
until 1997, the year of the Kyoto Protocol, when it reached a peak in the last decade (Mazur 1998; Carvalho and Burgess 2005). Since 2000, levels of media coverage reached new heights all around the world, spurred by factors such as $6^{\text {th }}$ Conference of the Parties to the United Nations Framework Convention on Climate change at The Hague and later the hurricane Katrina, Al Gore's documentary 'An Inconvenient Truth' and the Stern Review on the economics of climate change (cf. Boykoff and Roberts 2007). Even China has now decided to give prominence to this issue in its state-owned media. The English-language newspaper China Daily, for example, published over 600 articles in 2007, up from around 15-20 articles five years before.

Although the publication of the 4th IPCC Assessment Report in 2007 gained a significant prominence in the media, throughout the last two decades, the main triggers for media coverage seem to have been political factors. Particularly salient in this regard were the pronouncements of top level politicians on the issue and international summits, such as Rio's Earth summit in 1992, the Kyoto summit in 1997 and The Hague summit in 2000. This suggests that policy-makers have a strong power in setting the media agenda on climate change.

In fact, while scientists were the most frequent social actors present in the media (and the most frequent sources) in the mid-1980s, politicians quickly acquired greater visibility in the news about climate change (Trumbo 1996; Carvalho and Burgess 2005). Given what is at stake in climate change, it is not surprising that a variety of social actors have tried to shape the media debate with multiple arguments, proposals and worldviews being played in this arena. However, official discourses and political actors have been almost constantly dominant. Since early on in its public career, climate change has been appropriated by political figures to advance various types of agendas and in many cases to justify stalling on necessary action. Research indicates that the media have been an important ally in this process (e.g. Carvalho and Burgess 2005; Olausson 2009). While there have been some instances of critique and progressive thinking, the media have mainly been a forum to award visibility and legitimacy to the arguments of decision-makers.

\section{News-making and postnormal science}

Funtowicz and Ravetz (1993) forged the concept 'postnormal science' to refer to those cases where facts are uncertain, and where there is dispute over values. The stakes are high and the decisions urgent. Climate change fits this description neatly, thereby representing a number of challenges for news media reporting. This is a domain where forecasting is crucial: unlike other issues where what matters is knowing how things are, in climate change it is essential to have an idea of how things will be. Futurology necessarily involves a degree of uncertainty. Moreover, cause-effect links are not always as simple and linear in climate change as media discourse requires; a variety of causes are inter-related in a complex fashion, resulting in a number of different effects, some of which are diffuse. The time-frame of this slow unravelling issue does not easily match the frequency of news in the media either. Finally, its space-frames are at odds with a typical media division between 'national' and 'foreign' news.

It is worth inquiring how different factors in the news-making process interact with these characteristics of climate change. In one of the earliest studies on the media and the greenhouse effect, Wilkins and Patterson found that in order to make the news, slow-onset environmental hazards (which also included acid rain, ozone depletion, and Rhine River pollution) 'had to "find" an event' (1990: 16). Their conclusions pointed out that media representation was event-oriented, official sources-based, and tended to frame risk in terms of human activity rather than social and political contexts. 
Smith (2005), in his research with television news professionals and environmental issues, has observed that those involved tend to rely on a 'myth of detachment': that is, the belief that their role is to just to find the 'facts' and let people know about the 'truth'. This perception of the professional self is incompatible with the features of postnormal science. It may translate into a troubled communication of uncertainty, and thereby in a tendency to avoid reflecting upon the choices and values associated to mitigating climate change.

Research indicates that there have been significant international differences in the representation of uncertainty in climate change, with implications on the interpretation of different proposals for action (or inaction). In the US, a very significant aspect of media coverage is the prominence that has been awarded to the so-called climate sceptics or contrarians (at least until recently). Boykoff and Boykoff (2004) have shown that between $1995-2004,53 \%$ of newspaper stories in the so-called prestige press and $70 \%$ of TV segments on climate change in American news networks were 'balanced' in the presentation of the consensus views represented by the IPCC and those of the sceptics. This means that a small group of individuals, often lacking in scientific credibility (cf. Oreskes 2004) but resorting to loud marketing tactics, were awarded about the same time and prominence as a scientific community composed of thousands of scientists (whose work is regularly reviewed by the IPCC) and that has consistently maintained that the greenhouse effect is being enhanced by human activities. Boykoff and Boykoff have called this 'balance as bias', that is to say a 50/50 type of representation of scientific claims on climate change does not correspond to the size and/or professional authority of the two parts and in fact constitutes a biased representation of reality.

While Boykoff and Boykoff have highlighted the role of journalistic norms in the production of this image of controversy (see also Boykoff and Boykoff 2007), other explanations can be ventured. McCright and Dunlap (2000) point outside the media to the role of claims-makers and their pro-activity. The active engagement of the anti-environmental movement in the construction of alliances between conservative think tanks, fossil fuel interests and 'sceptic' scientists probably contributed to the disproportionate weight of 'contrarian' views in the mediai".

In a comparison between France and the US, Brossard, Shanahan and McComas (2004) found that in the coverage of climate change, Le Monde gave more emphasis to international relations issues than the New York Times, which tended to focus on domestic politics and give more attention to conflicts between scientists. The authors maintain that those differences reflect two distinct news-making cultures, with American journalism having a stronger tradition of 'objectivity' - and hence of hearing the two sides of an argument - and Le Monde having a tradition of favouring political over scientific issues.

In Germany, Weingart, Engels and Pansegrau found that there was a tendency for reporting the problem in catastrophist terms since the mid-1980s, attributable to the media's preference for 'sensationalism, negativity and unequivocal clearness' (2000: 275) but also to the German scientific and political discourses on climate change. A debate on uncertainty developed only later. More recently, Peters and Heinrichs (2008: 34) have demonstrated that in the last few years the German media 'construction' of climate change has been defined by a proximity to science and the IPCC, and that there is a 'great consonance in characterizing the risks of global climate change'. This symbolic environment turns climate change into a 'legitimate field for political action'.

In the United Kingdom, climate change 'sceptics' have gained some visibility in the conservative press (Carvalho, 2007). Analyses of this country's media discourses have shown important differences in media representations of climate change. The ideological culture of each news organization appears to have shaped many aspects of media coverage with right wing news outlets often displaying positions of resistance to the changes that 
would need to be put in place to mitigate GHG emissions (Carvalho and Burgess 2005; Carvalho 2007). Besides professional news-making norms and the agency of social actors, the media's depictions of climate change may therefore also depend on the institutional ethos of news organizations (including their perceived audiences' expectations, preferences and values). The wider ideological and symbolic environments of each country may also play a role. Dispensa and Brulle (2003) have argued that the type of government, economic structures and industrial interests may as well lead to different forms of media coverage of climate change across countries.

\section{Scale, engagement and modes of representation}

Studies indicate that media representations of climate change in France (Brossard, Shanahan and McComas 2004), Sweden (Olausson 2009) and Portugal (Carvalho and Pereira 2008) have been dominated by the international politics of climate change. While this can be expected when we think about the relevance of international negotiations for the management of climate change, it can also be argued that the national and the local are the appropriate levels to act upon the sources of the problem. Yet, sustained analysis of the possibilities for local policy-making on climate change is featured in the media only rarely. Hence, while climate change may be represented as a tragic threat, debate on the climate impacts of a new road or a new housing development does not necessarily take place in a meaningful way. There is an apparent disconnect between climate change and specific sources of GHG emissions and between the global and local scales.

Lorenzoni, Nicholson-Cole and Whitmarsh (2007) have demonstrated that many of the barriers to citizen engagement with climate change are related to information, such as a perceived information overload or lack of access to relevant details. While the media have privileged the global level for action on climate change and emphasised 'distant' effects, such as ice retreating in the polar regions, representing climate change as more tangible (and thus more manageable) has been shown to be useful for the common citizen. For instance, O'Neill (2008) has concluded that non-experts prefer climate change 'icons' that are locally-relevant, such as flooding in the Norfolk Broads in the case of British public opinion. While the cognitive aspects of communication have been traditionally considered most important, she shows that affective engagement is also crucial.

This takes us to visual depictions of climate change, a key area that has been relatively under-researched. Environmental problems are not easily captured by the human senses; this makes efforts to improve public awareness - let alone mobilize collective action to address their causes - much more difficult. Climate change is particularly 'invisible,' given the nature of the problem and the temporal and spatial scales that characterize it. Therefore in a culture where visual communication is not only pervasive but often profoundly shapes the meaning of an issue, product or idea, it is not surprising that many have felt the need to find visual representations of climate change.

To date, a diverse imagery has been associated with climate change issues; for example, meteorological phenomena (e.g. droughts, storms, flooding); sources of GHGs (e.g. cars, factories, power stations); and 'season'-related elements (e.g. early flowers). Organizations like Greenpeace have used photography to provide visual 'proof' that climate change is taking place: pictures of retreating glaciers are one of the striking examples of this. Doyle (2007) has pointed out certain tensions involved in trying to represent climate change through photography, however. For example, because photographs can only document what has already happened, efforts to make the issue depend on the 'truth effect' of images risk undermining preventive actions. Doyle argues that given the 'representational limitations of the visual $(\ldots)$, rather than proving that climate change is real through visible means, it might be more useful for environmental NGOs, and environmental scientists, to persuade the public that not all environmental problems can be seen' (2007: 147). 


\section{Between catastrophism and ecological modernization}

We will now turn to a brief analysis of the prevaliling tones, ideas and values in media discourses on climate change. In a study of the British media (Ereaut and Segnit 2006), it has been found that there are two main 'discursive repertoires': one alarmist and one optimistic. Hulme (2007) and other scholars have also called attention to the media emphasis on fear in representing climate change. In fact, examples abound, in the UK's media and in other countries, of visions of imminent doom associated with climate change (e.g. New York being flooded by the Atlantic Ocean; the planet going up in flames; the end of life on Earth). Some analysts have labelled this kind of media imagery as 'climate porn' (Ereaut and Segnit 2006) and have linked it to excessive sensationalism and commercialism.

Research has shown that a focus on catastrophe and fear may lead to paralysis. Some people may be led to think that climate change is out of their control and that there is nothing they can do. Instead of attempting to cut down emissions, they may adopt reactive behaviours, such as purchasing more air-conditioners in anticipation of potential heat waves. Others may have reactions of disbelief when faced with very dramatic scenarios (cf. Lowe 2006). The conclusion to be derived from this is not that the negative impacts of climate change should be removed from the public sight, however. Rather, it is recognised that this kind of imagery plays a role in terms of maintaining a sense of urgency. As such, it is a form of pressure that can be placed upon politicians to encourage them to address the problem, albeit one that has to be handled carefully so as to avoid public apathy, fatalism or scepticism. In this line, it is worth mentioning that Ereaut (2008) has noted that between 2006 and 2007 there has been a move in the British media towards moderation in language: that is, a move from 'alarmism' to 'alarm'.

Situated against the alarmist discourse is a more optimistic reading of climate change in the media. It comes in many shades, from the conviction that warming will be good for us to a faith in human ability to act in a rational way to avoid climate change. One of the most pervasive optimistic discourses is 'ecological modernization', which is a belief in a win-win scenario where economic and technological investment oriented to mitigating GHG emissions leads to economic gains and the creation of jobs (cf. Hajer 1995). This is an idea that is commonly advanced by governments, to whom the prospect of economic growth resulting from environmental protection is obviously highly attractive. The problem with this discourse is that it may lead us to believe that no transformations are required in our forms of consumption, mobility and lifestyles, more generally, which is certainly not realistic.

Still, this is a rhetorically powerful discourse. Indeed, the corresponding notion of sustainable development, with its ambiguities and open texture (Torgerson 1995), has been highly influential as well. To a large extent it has rendered climate change into something amenable to international management and technological solutions. Thus climate change has been commodified (for instance by emissions trading plans), and subjected to a technomanagerial approach - instead of remaining as a crucial political matter, subject to ideological debate, scrutiny and contention.

It is readily apparent that the news media have aided the institutionalization (cf. Hajer 1995) of these discourses. In most countries, there is little to be found in the mainstream media in terms of critical debate in relation to these hegemonic views. Olausson (2009) has pointed out that in the Swedish print media the construction of climate change takes place in a largely uncontested discursive setting' with the media discourse essentially reproducing and legitimating the political discourse. Carvalho and Pereira (2008) have shown that there is a similar situation in Portugal. In the UK, while there has been some dispute in discourses on climate change on the pages of the quality newspapers, for example (Carvalho and Burgess 
2005), the general tendency has been to stay inside the parameters of free-market capitalism, industrialism and neo-liberalism.

The internet is the space where most alternative voices can be found. A myriad of websites offer critical insight, advance specific policy proposals, and create opportunities for discussion and empowerment of citizens (e.g. Global Climate Campaign; Global Commons Institute; Rising Tide). Nevertheless, this is an area that is largely under-researched. Analysing these discursive practices and understanding their social, cultural and political effects is a key goal for communication researchers in the next few years.

\section{Entertainment, advertising and the evolving meanings of climate change}

Up until this point, this chapter has focused mainly on the media genre of news and associated 'information-type' discourses. Based on the analysis of non-news types of media messages, Shanahan and McComas (1999) have argued that rather then environmental consciousness, the media, as a whole, reinforce values like progress, materialism and technology. Television, magazines and other media contribute to creating a social environment that is at odds with environmental protection. Rather, they are seen to contribute to the maintenance of the status quo, thereby dissuading audiences that they can or should play a role in solving environmental problems.

A long-term cultivation-type analysis of a person's exposure to all types of media would reveal an image irreconcilable with climate protection. In fact, the media constantly spread appeals to consumption and mobility. Most forms of fictional and entertainment content refer to a lifestyle characterized by material comfort and wellbeing, and tend to instil a desire for purchasing more and more goods and for 'getting away' all the time.

In the omnipresent field of advertising, discourses addressing climate change are increasingly common. As public expectations grow in relation to the environmental performance of business, many companies have engaged in greening their image or brands. Green marketing is no longer the exclusive of Body Shop: almost every car-maker now suggests that we can save the climate by purchasing their new cars and most fuel companies seem to have now gone Beyond Petroleum. Behind these messages, the degree of substantive action taken by companies towards avoiding harm to the environment is certainly variable, but the discursive hegemony of 'green growth' is in itself a revealing sign of the current times.

In these dynamic processes, climate change keeps gaining new meanings, sometimes involving a true symbolic subversion (Linder 2006). One example of this can be found in a campaign for the clothes brand Diesel, entitled 'Global warming ready'. The campaign uses climate-altered scenarios, like Venice with red araras or a flooded London, not to generate concern or to call attention to the consequences of some forms of consumption, but to promote more consumption in a 'cool' new world where models wear Diesel's clothes and sunglasses in defiance of change.

\section{The future of media practice and research}

The speed at which the media field continues to change is remarkable, opening up new opportunities to develop strategies for communicating climate change. Technology has been creating possibilities for 'richer storytelling and more prominent and fuller expression of diverse public voices' (Smith 2005: 1480). Greater interactivity, programming that mixes different genres and media, 'the capacity to build future scenarios and to represent affective dimensions as well as "the facts"' (ibid), are among the potential to be explored by media practitioners and researchers alike. 
An important scope for social debate and for research is presented by alternative media, especially the internet. In recent years, an array of citizen movements on climate change has emerged and made creative uses of online communication. As mentioned above, it is important that scholars turn their attention to the struggles over meaning transpiring in this vast arena and seek to contribute to understanding how its uses have been shaping social and political action.

For both 'new' and 'old' media, as well as for research, a number of professional and ethical issues deserve continuous rethinking. For instance, the media could play an important role in monitoring the performance of corporations in terms of GHG emissions, exposing the climate impacts of big corporations, and making news about the emissions cuts that corporations could be making and are not making. Instead, these aspects are almost completely absent from the news coverage. The same kinds of checks could be made on government policies, which should be scrutinised in cross-sectoral ways. Promoting the public accountability of institutions could help to engage and empower citizens.

The relation between the media, public opinion and policy action is complex and dynamic, with successive circuits of production and circulation of messages - as well as multiple forms of decoding and appropriation of meanings in everyday life - traversing public life. It is a process where numerous factors play, from journalistic pressures to economic drivers to political contexts (cf. Carvalho and Burgess 2005). Analysing the evolution of media representations of climate change will remain an important goal for research as it helps us to better comprehend the dynamics of mediation. That is, how - and why - certain definitions of climate change become hegemonic, however fleetingly, while others are suppressed or reduced to marginal positions in public debates.

It is extremely unusual for an issue to sustain such an intense and prolonged mediatization as climate change has done in the last two decades. Neverla (2008) has argued that it has become a new 'grand narrative', a sort of journalistic 'meta-perspective' or 'superframe', which facilitates greater connectivity across otherwise disparate issues. There is little doubt that climate change has become associated with a variety of questions, problems and themes, such as energy, security, resource-management, technological innovation and many others. Spelling out and interpreting these connections is an important responsibility for media professionals. It is similarly worth paying even closer attention to the ways in which journalism itself is evolving in this regard, and what implications this may entail for our future.

\section{Acknowledgement}

This chapter builds on research done for the project "The Politics of Climate Change: Discourses and Representations", funded by the Portuguese Fundação para a Ciência e a Tecnologia (POCI/COM56973/2004).

\section{References}

Boykoff, M. and Boykoff, J. (2004) 'Balance as bias: Global warming and the US prestige press', Global Environmental Change, 14: 125-136.

Boykoff, M. and Boykoff, J. (2007) 'Climate change and journalistic norms: A case-study of US mass-media coverage', Geoforum, 38: 1190-1204.

Boykoff, M. and Roberts, J. T. (2007) Media Coverage of Climate Change: Current Trends, Strengths, Weaknesses, United Nations Development Report, Occasional paper, 2007/3. 
Brossard, D., Shanahan, J. and McComas, K. (2004) 'Are issue-cycles culturally constructed? A comparison of French and American coverage of global climate change', Mass Communication \& Society, 7 (3): 359-77.

Cabecinhas, R., Lázaro, A. and Carvalho, A. (2008) 'Media use and social representations of climate change', in A. Carvalho (ed.) Communicating Climate Change: Discourses, Mediations and Perceptions (e-book), Braga: Centro de Estudos de Comunicação e Sociedade, Universidade do Minho. E-book available from: http://www.lasics.uminho.pt/ojs/index.php/climate_change

Carvalho, A. (2007) 'Ideological cultures and media discourses on scientific knowledge. Rereading news on climate change', Public Understanding of Science, 16 (2): 223-43.

Carvalho, A. and Burgess, J. (2005) 'Cultural circuits of climate change in UK broadsheet newspapers, 1985-2003', Risk Analysis, 25 (6): 1457-69.

Carvalho, A. and Pereira, E. (2008) 'Communicating climate change in Portugal: A critical analysis of journalism and beyond', in A. Carvalho (ed.) Communicating Climate Change: Discourses, Mediations and Perceptions (e-book), Braga: Centro de Estudos de Comunicação e Sociedade, Universidade do Minho. E-book available from: http://www.lasics.uminho.pt/ojs/index.php/climate_change

Corbett, J. and Durfee, J. (2004) 'Testing public (un)certainty of science: Media representations of global warming', Science Communication, 26 (2): 129-51.

Dispensa, J. M. and Brulle, R. J. (2003) 'Media's social construction of environmental issues: Focus on global warming - A comparative study', International Journal of Sociology and Social Policy, 23 (10): 74-105.

Doyle, J. (2007) 'Picturing the Clima(c)tic: Greenpeace and the Representational Politics of Climate Change Communication', Science as Culture, 16:2, 129-150.

Ereaut, G. (2008) 'Warm Words. The UK discourse of climate change: implications for whatand how-we can communicate', paper presented at the workshop 'Engaging the public in climate change and energy demand reduction', UKERC, Oxford, 7-8 October.

Ereaut, G. and Segnit, N. (2006) Warm Words: How are we telling the climate story and can we tell it better? London: Institute for Public Policy Research.

Funtowicz, S. and Ravetz, J. (1993) 'Science for the Post-Normal Age', Futures, 25:7, 73955.

Global Climate Campaign. Online. Available < http://www.globalclimatecampaign.org//> (accessed 10 October 2008).

Global Commons Institute. Online. Available <http://www.gci.org.uk//> (accessed 10 October 2008).

Hajer, M. (1995) The Politics of Environmental Discourse. Ecological Modernization and the Policy Process, Oxford: Clarendon Press.

Hawkins, A. (1993) 'Contested ground: international environmentalism and global climate change', in R. Lipschutz and K. Conca (eds) The State and Social Power in Global Environmental Politics, New York: Columbia University Press. 
Hulme, M. (2007) 'Newspaper scare headlines can be counter-productive', Nature 445 (22 February): 818.

IPCC (2007) Climate Change 2007: Synthesis Report. Online. Available: <http://www.ipcc.ch/ipccreports/ar4-syr.htm> (accessed 4 September 2008).

Linder, S. (2006) 'Cashing-in on risk claims: On the for-profit inversion of signifiers for "global warming"', Social Semiotics, 16 (1): 103-32.

Lorenzoni, I., Nicholson-Cole, S., and Whitmarsh, L. (2007) 'Barriers perceived to engaging with climate change among the UK public and their policy implications', Global Environmental Change, 17: 445-59.

Lowe,T. D. (2006) Is this climate porn? How does climate change communication affect our perceptions and behaviour?, Tyndall Centre Working Paper 98, Norwich.

Mazur, A. (1998) 'Global Environmental Change in the News', International Sociology, 13 (4): 457-72.

McCright, A. and Dunlap, R. (2000) 'Challenging global warming as a social problem: An analysis of the conservative movement's counter-claims', Social Problems, 47 (4): 499-522.

Neverla, I. (2008) 'The IPCC reports 1990-2007 in the media. A case-study on the dialectics between journalism and natural sciences', paper presented in the panel 'A global dialogue on climate change?', ICA Conference 'Global Communication and Social Change', Montreal, 22-26 May.

Olausson, U. (2009) 'Global warming-global responsibility? Media frames of collective action and scientific certainty', Public Understanding of Science, 18: 421-436.

O'Neill, S. (2008) An Iconic Approach to Representing Climate Change, Unpublished PhD thesis, University of East Anglia

Oreskes, N. (2004) 'Beyond the ivory tower: The scientific consensus on climate change', Science, 306 (5702): 1686.

Peters, H. P. and Heinrichs, H. (2008) "Legitimizing climate policy: The "risk construct" of global climate change in the German mass media', International Jounal of Sustainability Communication, 3: 14-36.

Pew Research Center for the People and the Press (2001) 'Bush Unpopular in Europe, Seen as Unilateralist'. Online. Available <http://pewglobal.org/reports/print.php?PagelD=39> (accessed 21 October 2001).

Rising Tide. Online. Available <http://risingtide.org.uk/> (accessed 10 October 2008).

Shanahan, J. and McComas, K. (1999) Nature Stories: Depictions of the Environment and their Effects, Cresskill, NJ: Hampton Press.

Smith, J. (2005) 'Dangerous news: Media decision making about climate change risk', Risk Analysis, 25 (6): 1471-82.

Torgerson, D. (1995) 'The uncertain quest for sustainability: public discourse and the politics of environmentalism', in F. Fischer and M. Black (eds) Greening Environmental Policy. The Politics of a Sustainable Future, Liverpool: Paul Chapman. 
Trumbo, C. (1996) 'Constructing climate change: Claims and frames in US news coverage of an environmental issue', Public Understanding of Science, 5: 269-73.

Weingart, P., Engels, A., and Pansegrau, P. (2000) 'Risks of Communication: Discourses on Climate Change in Science, Politics, and the Mass Media', Public Understanding of Science, 9: 261-83.

Wilkins, L. and Patterson, P. (1990) 'Risky business: covering slow-onset hazards as rapidly developing news', Political Communication and Persuasion, 7: 11-23.

Wilson, K. (1995) 'Mass media as sources of global warming knowledge', Mass Communication Review, 22 (1-2): 75-89.

Yale/Gallup/ClearVision (2007) 'American opinions on global warming'. Online. Available < http://environment.yale.edu/news/5305/american-opinions-on-global-warming/> (accessed 22 September 2008).

\footnotetext{
i For ease of access, the majority of studies have focused on the print media, especially newspapers, so references to those will be overrepresented.

ii This kind of representation of climate change has contributed to confuse the public with $40 \%$ of citizens saying that they think that there is a lot of disagreement among scientists about whether global warming is happening (Pew Research Center for the People and the Press 2001). It has also contributed to citizen and political inaction, and fed a tendency for American citizens to disregard political responsibility on this issue: opposition to George W. Bush's decision to abandon the Kyoto protocol in 2001 was much bigger in other countries than in the USA (Yale/Gallup/ClearVision 2007).
} 